Original article

\title{
Income-based inequality in full immunization coverage of children aged 12-23 months in Eastern India: A decomposition analysis
}

\author{
Shantanu Sharma ${ }^{\mathrm{a}, \mathrm{b}, *}$, Sonali Maheshwari ${ }^{\mathrm{b}}$, Ajit Kumar Jaiswal ${ }^{\mathrm{c}}$, Sunil Mehra ${ }^{\mathrm{b}}$ \\ ${ }^{a}$ Department of Clinical Sciences, Lund University, Skåne University Hospital, S-20502 Malmö, Sweden \\ ${ }^{\mathrm{b}}$ MAMTA Health Institute for Mother and Child, Delhi, India \\ ${ }^{c}$ International Institute for Population Sciences, Mumbai, India
}

\section{A R T I C L E I N F O}

\section{Keywords:}

Child mortality

Infant

Vaccination

Vaccine preventable diseases

\begin{abstract}
A B S T R A C T
Introduction: Notably, less than two-thirds of under-5 children received full immunization in 2016 in India. It is critical to understand the inequalities in access to immunization for determining an effective health policy agenda to ensure universal health coverage. Hence, we performed a study to assess the determinants of incomebased inequality in the full immunization of children aged 12-23 using Fairlie decomposition analysis.

Methods: This cross-sectional study was a part of a community-based project that aimed to improve maternal and child health in the backward states of India, namely Bihar and Assam. The study was conducted in the rural and urban areas of Munger and Darrang districts of Bihar and Assam, respectively. The degree of income-related inequality in full immunization coverage was obtained through the concentration index. The Fairlie decomposition was employed to quantify the absolute contribution of socio-demographic factors explaining the group differences (higher or lower income) in the probability of having full immunization.

Results: There were 73 fully and 82 non-fully immunized children. The concentration curve was lying above the line of equality, which implied that full immunization coverage was concentrated towards the lower-income group. Maternal education (7.5\%) and place of residence $(5.1 \%)$ widened the inequality gap, and caste $(-13.5 \%)$ and age of the child $(-2.5 \%)$ narrowed down the inequality gap for full immunization among lower and higher-income groups.

Conclusions: The socio-economic inequalities in access to full immunization can be mitigated by multi-sectoral interventions with a focus on children with less-educated mothers and living in urban slums.
\end{abstract}

\section{Introduction}

Immunization, one of the cost-effective public health interventions, has a crucial role in achieving 14 out of 17 sustainable development goals (SDG). ${ }^{1}$ It is estimated that for USD 1 invested in immunization, USD 16 are saved in healthcare costs, lost wages, and lost productivity due to morbidity and mortality. ${ }^{2}$ Infectious diseases, preventable by vaccines, can tip unimmunized children into a malnourished state and malnourished children into death. Currently, immunization prevents 2-3 million deaths of under-5 every year. ${ }^{3}$

India's universal immunization program is the largest in the world, with over 9 million sessions held and 26.7 million infants vaccinated in a year. Started in 1978 with six vaccines, the national immunization program in the country has been expanded and now provides free of cost
12 vaccines. ${ }^{4}$ However, less than two-thirds of the under-5 children received full immunization in 2016, according to the National Family Health Survey-4 (NFHS-4). Despite steady progress in the routine childhood immunization coverage in India over 30 years, there are wide disparities or inequalities within the population subgroups. ${ }^{5}$ In the move to achieve the global target of $90 \%$ immunization coverage, the government of India introduced multiple strategies, including the launch of Mission Indradhanush, electronic vaccine intelligence network (eVIN), etc. Furthermore, the government, along with non-governmental organizations, is generating awareness among people for complete immunization. $^{5}$

It is imperative to understand the factors that act as barriers to full immunization among under-5. The theory of social determinants of health spotlights factors, such as education and income, that may

\footnotetext{
* Corresponding author. Department of Clinical Sciences, Lund University, Skåne University Hospital, S-20502 Malmö, Sweden.

E-mail addresses: shantanusharma145@gmail.com, shantanusharma@mamtahimc.in (S. Sharma), sonalim@mamtahimc.in (S. Maheshwari), ajitjaiswal20@ gmail.com (A.K. Jaiswal), dr_mehra@mamtahimc.in (S. Mehra).
} 
influence an individual's action for disease prevention. ${ }^{6}$ It is critical to understand these inequalities in access to health services, such as immunization, for determining an effective health policy agenda to ensure universal health coverage. ${ }^{7}$ The inequalities in health by socio-demographic characteristics, including wealth, have been explored in the previous studies. ${ }^{8,9}$ We argue that wealth inequalities do contribute to the inequality in immunization coverage.

A few studies have been conducted in the past that have assessed factors contributing to the income-based inequality in immunization coverage. $^{10-12}$ Our study was a part of a community-based project that aimed to improve maternal and child health in the two most backward states of India, namely Bihar and Assam. One of the objectives of the project was to improve the immunization coverage of under- 5 children in the intervention areas by addressing the determinants that affect them. Hence, the objective of the present study was to assess the determinants of income-based inequality in the full immunization coverage of 12-23 years old children using Fairlie decomposition analysis.

\section{Methods}

\subsection{Study design and setting}

We conducted this community-based cross-sectional study in the two states of India, namely Bihar and Assam. Bihar is situated in the East and Assam in the North-East region of the country. Munger district in Bihar, and Darrang in Assam were the intervention areas. Munger, a district situated south-east to the capital of Bihar, Patna, has a population of 1.3 million, $77 \%$ literacy rate, a sex ratio of 986 females per 1000 males, and an infant mortality rate of 48 per 1000 live births. ${ }^{13,14}$ Darrang, a district situated north-east to the capital of Assam, Guwahati, has a population of 0.9 million, $65.5 \%$ literacy rate, a sex ratio of 969 females per 1000 males, and an infant mortality rate of 69 per 1000 live births. ${ }^{13,14}$ Rural areas from Munger and Darrang and urban areas from Munger were chosen for the study. There were a total of 45 urban wards and 5-Gram Panchayats (3 from Munger and 2 from Darrang) selected for the study. Gram Panchayats are the local governance units in Indian villages.

\subsection{Sample size}

The immunization coverage in Munger was $62 \%$ and $40 \%$ in Darrang. Considering the $40.0 \%$ immunization coverage, ${ }^{13}$ at $95 \%$ confidence level, $10 \%$ absolute error, design effect of 1.5 , the sample size was calculated at 145 . So the minimum sample size required for detecting a statistical difference was 145 .

\subsection{Sampling and sample selection}

Listing of all the urban wards and Gram Panchayats were performed at the beginning. The required number of primary sampling units (urban wards and Gram Panchayats) were chosen randomly using probability proportional to size. Systematic random sampling was employed for the selection of households. The mothers of 12-23 years old children were interviewed. The study participants were approached only once for the survey. In case the participants were not found at home, the second visit was not paid to that house, and a house adjacent to that one was selected.

\subsection{Ethical consideration}

MAMTA Institutional Review Board (MIRB) granted ethical clearance for this study. Mothers of 12-23 years old children were explained the objectives of the study, and their due consent was obtained.

\subsection{Study tool}

The questionnaire consisted of questions on socio-demographic characteristics, including the age of mother and child, mother literacy (literate or illiterate), parity (number of children mother had), religion (Hindus, Muslim, Christian, and Sikh), social caste (marginalized classes, such as scheduled caste, tribe or other backward classes, or nonmarginalized class), and monthly family income. The immunization history of the 12-23 years old children was obtained by viewing the immunization card of the child. Full immunization was defined as the receipt of one dose of Bacille Calmette-Guérin (BCG), three doses of oral polio, three doses of combined Diptheria, Pertussis, and Tetanus (DPT), and one dose of measles vaccine. ${ }^{10}$ The interview was administered by trained research investigators.

\subsection{Statistical analysis}

The data were dichotomized into fully immunized and non-fully immunized categories. The continuous variables were represented as median (Interquartile Range, IQR), and categorical variables as frequency and percentages. The statistical difference in the distribution of socio-demographic variables between fully immunized and non-fully immunized 12-23 years old children was obtained through the chisquare test (categorical variables) or Mann Whitney $U$ test (continuous data). The degree of income-related inequality in full immunization coverage was obtained through the concentration index. We used the Erreygers index for binary variables, which is rank dependent, to calculate the concentration index. ${ }^{15}$

To identify the underlying causes of the gap in full immunization between low and high-income groups, the technique of decomposition had been used, which is the most common approach used to identify and quantify inter-group differences. The method is commonly attributed to Blinder (1973) and Oaxaca (1973). ${ }^{16}$ This technique, however, is not appropriate if the outcome variable is dichotomous, such as full immunization status. Hence, we used the Fairlie decomposition technique, which is the extension of the Blinder-Oaxaca decomposition method. Fairlie method is used appropriately for binary models to decompose the group differences into contributions that can be attributed to different factors. ${ }^{17}$ This method of decomposition allows us to quantify the absolute contribution of factors explaining the group differences (high or low-income groups) in the probability of having full immunization among children. All the analysis was performed using STATA version 16.0 (StataCorp. 2019. Stata Statistical Software: Release 16. College Station, TX: StataCorp LLC). We considered p-value $<0.05$ as statistically significant.

\section{Results}

Table 1 shows the socio-demographic attributes of the two groups (fully immunized or non-fully immunized). Nearly two-thirds of mothers of fully immunized or non-fully immunized children belonged to the age group $>21$ years. A higher proportion of non-fully immunized children belonged to the non-Hindu group compared to Hindu $(p=0.003)$. A significantly large number of children were fully immunized who lived in rural areas compared to urban areas $(\mathrm{p}=0.01)$.

Fig. 1 shows a concentration curve depicting the income-based inequality in the full immunization coverage in children. The cumulative proportion of children aged 12-23 months with full immunization was plotted against the cumulative percentage of the population (ranked by income quintile). The concentration curve lies above the line of equality. This implies that full immunization coverage is concentrated towards the lower-income proportion of the population.

A positive contribution presents that a particular variable has increased the gap of full immunization from lower to higher-income category and vice-versa. The detailed estimates for decomposition analysis of the gap of full immunization are presented in Table 2. 
Table 1

Socio-demographic attributes of the fully and non-fully immunized 12-23 years old children.

\begin{tabular}{|c|c|c|c|}
\hline Variables & $\begin{array}{l}\text { Full } \\
\text { immunization } \\
\text { Yes }(\mathrm{n}=73) \mathrm{N} \\
(\%)\end{array}$ & $\begin{array}{l}\text { Full } \\
\text { immunization } \\
\text { No }(\mathrm{n}=82) \mathrm{N} \\
(\%)\end{array}$ & $\begin{array}{l}\mathrm{p}- \\
\text { value }\end{array}$ \\
\hline $\begin{array}{l}\text { Mothers' age (years) } \\
\text { 15-21 } \\
\text { More than } 21\end{array}$ & $\begin{array}{l}27(37.0) \\
46(63.0)\end{array}$ & $\begin{array}{l}28(34.0) \\
54(66.0)\end{array}$ & 0.7 \\
\hline $\begin{array}{l}\text { Mother literacy } \\
\text { Yes } \\
\text { No }\end{array}$ & $\begin{array}{l}59(80.8) \\
14(19.2)\end{array}$ & $\begin{array}{l}66(80.5) \\
16(19.5)\end{array}$ & 0.9 \\
\hline $\begin{array}{l}\text { Parity } \\
\text { One } \\
\text { Two and above }\end{array}$ & $\begin{array}{l}48(65.7) \\
25(34.3)\end{array}$ & $\begin{array}{l}50(61.0) \\
32(39.0)\end{array}$ & 0.5 \\
\hline $\begin{array}{l}\text { Age of children (months) } \\
12-17 \\
18-23\end{array}$ & $\begin{array}{l}27(37.0) \\
46(63.0)\end{array}$ & $\begin{array}{l}31(37.8) \\
51(62.2)\end{array}$ & 0.9 \\
\hline $\begin{array}{l}\text { Caste } \\
\text { Marginalized classes } \\
\text { Non-marginalized classes }\end{array}$ & $\begin{array}{l}31(42.5) \\
42(57.5)\end{array}$ & $\begin{array}{l}44(53.6) \\
38(46.4)\end{array}$ & 0.1 \\
\hline $\begin{array}{l}\text { Religion } \\
\text { Hindu } \\
\text { Non-Hindu }\end{array}$ & $\begin{array}{l}58(79.5) \\
15(20.5)\end{array}$ & $\begin{array}{l}47(57.3) \\
35(42.7)\end{array}$ & 0.003 \\
\hline $\begin{array}{l}\text { Place of residence } \\
\text { Rural } \\
\text { Urban slums } \\
\text { Missing }\end{array}$ & $\begin{array}{l}48(65.7) \\
25(34.3) \\
0\end{array}$ & $\begin{array}{l}36(45.0) \\
44(55.0) \\
2\end{array}$ & 0.01 \\
\hline $\begin{array}{l}\text { Median monthly family income } \\
(I Q R)^{\mathrm{a}} \text { in Indian Rupees }\end{array}$ & $\begin{array}{l}4000 \\
(2000-6500)\end{array}$ & $\begin{array}{l}5000 \\
(3000-8000)\end{array}$ & 0.12 \\
\hline
\end{tabular}

p-value $<0.05$ was considered statistically significant.

${ }^{\text {a }}$ Mann Whitney $U$ test was performed.

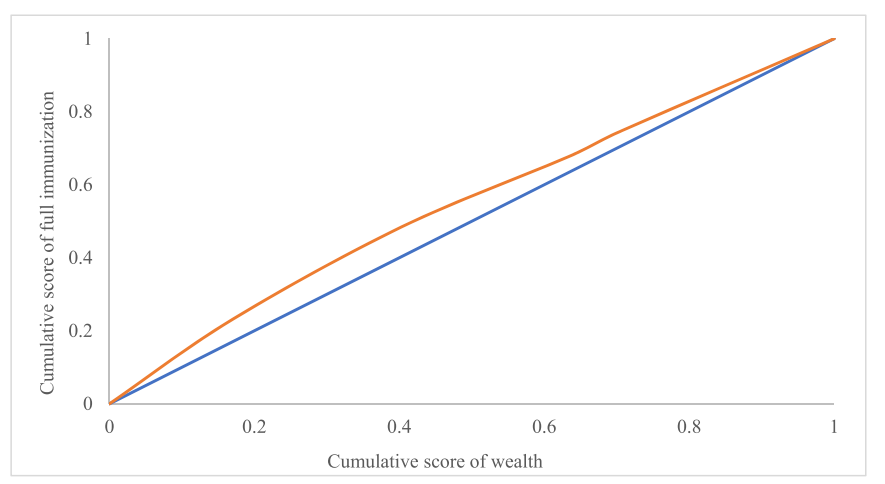

Fig. 1. Concentrative curve for full immunization among children aged 12-23 months. Fig. 1 presents concentrative curve (orange line) for full immunization among children aged 12-23 months. It depicts that full immunization was concentrated among lower-income children (CI: 0.10).

Maternal education (7.5\%) and place of residence (5.1\%) widened the gap for full immunization among the lower and higher-income categories. However, caste $(-13.5 \%)$ and age of the child $(-2.5)$ had narrowed down the gap for full immunization among lower and higherincome groups. The predictive probability for full immunization among the lower-income group was 0.57 , whereas, among the higherincome group, it was 0.39 .

\section{Discussion}

A wide range of socio-demographic, economic, and behavioural factors affect the immunization coverage in low- and middle-income countries like India. We found that inequality favoured the lowerincome group in the study areas from Bihar and Assam. The immunization coverage gap due to income-based inequality was widened by maternal education and place of residence and narrowed by caste and
Table 2

Decomposition results for contribution of predictor variables explaining the gap of full immunization among children (12-23 months) by higher and lowerincome group, $(\mathrm{N}=153)$.

\begin{tabular}{|c|c|c|c|c|}
\hline Variables & \multicolumn{2}{|c|}{ Coefficient $^{\mathrm{a}}$} & Standard error & $\%$ contribution \\
\hline \multicolumn{5}{|l|}{ Mothers' age (years) } \\
\hline $15-21$ & \multicolumn{2}{|l|}{ Ref. } & & \multirow[t]{2}{*}{-0.1} \\
\hline More than 21 & \multicolumn{2}{|l|}{0.000} & 0.004 & \\
\hline \multicolumn{5}{|l|}{ Mothers Literacy } \\
\hline No & \multicolumn{2}{|l|}{ Ref. } & & \multirow[t]{2}{*}{7.5} \\
\hline Yes & \multicolumn{2}{|l|}{0.013} & 0.021 & \\
\hline \multicolumn{5}{|l|}{ Parity } \\
\hline One & \multicolumn{2}{|l|}{ Ref. } & & \multirow[t]{2}{*}{1.1} \\
\hline Two and above & \multicolumn{2}{|l|}{0.002} & 0.016 & \\
\hline \multicolumn{5}{|l|}{ Age of children (months) } \\
\hline $12-17$ & \multicolumn{2}{|l|}{ Ref. } & & \multirow[t]{2}{*}{-2.5} \\
\hline $18-23$ & \multicolumn{2}{|l|}{-0.004} & 0.005 & \\
\hline \multicolumn{5}{|l|}{ Caste } \\
\hline Marginalized classes & \multicolumn{2}{|l|}{ Ref. } & & \multirow[t]{2}{*}{-13.5} \\
\hline Non- Marginalized classes & \multicolumn{2}{|l|}{-0.024} & 0.017 & \\
\hline \multicolumn{5}{|l|}{ Religion } \\
\hline Hindu & \multicolumn{2}{|l|}{ Ref. } & & \multirow[t]{2}{*}{-1.6} \\
\hline Non-Hindu & \multicolumn{2}{|l|}{-0.003} & 0.009 & \\
\hline \multicolumn{5}{|l|}{ Place of residence } \\
\hline Urban slums & \multicolumn{2}{|l|}{ Ref. } & & \multirow[t]{2}{*}{5.1} \\
\hline Rural & 0.009 & & 0.007 & \\
\hline \multicolumn{2}{|l|}{ Number of observations } & \multicolumn{2}{|l|}{153} & \\
\hline \multicolumn{2}{|c|}{ No. of observations (lower-income) } & \multicolumn{2}{|l|}{74} & \\
\hline No. of observations (higher & ncome) & 79 & & \\
\hline $\begin{array}{l}\text { Predictive probability for } \mathrm{f} \\
\text { immunization among lov } \\
\text { income group (P1) }\end{array}$ & & 0.568 & & \\
\hline $\begin{array}{l}\text { Predictive probability for } \mathrm{f} \\
\text { immunization among hig } \\
\text { income group (P2) }\end{array}$ & & 0.392 & & \\
\hline Difference (P1-P2) & & 0.175 & & \\
\hline Total explained & & -0.007 & & \\
\hline Total contribution & & -4.2 & & \\
\hline
\end{tabular}

${ }^{a}$ None of the associations were significant $(p>0.05)$.

age of the child.

The literacy rate of women in Bihar is low compared to many states in India, though it had increased substantially in the last decade from $33 \%$ in 2001 to 53\% in 2011. Female literacy in Assam is comparatively higher than Bihar (66\%). The maternal education across the study areas is nearly similar to the states (58\% in Darrang and $62 \%$ in Munger). ${ }^{18}$ In the present study, $80 \%$ of women reported to be literate (read or write in one language), which is higher than the district averages. This could probably be due to less generalized sampling. Women's education is an important facilitator towards their empowerment and transformation in the lives of families, especially children. Studies highlighted that increased maternal education is associated with reduced child mortality, malnutrition, and enhanced growth and development. ${ }^{19,20}$

Likewise, early marriage and childbearing contribute to poor maternal and child health. More than one-third of the mothers of fully or non-fully immunized children in our study were aged less than 21 years. Studies reported early childbearing (less than 19 years) as high as $41 \%$ in Bihar and $22-25 \%$ in Assam. ${ }^{21,22}$ Early childbearing negatively impacts the educational attainment of women resulting in women's economic dependency and poor maternal and child health. It has been documented that early marriage and childbearing are associated with poor reproductive health, increased risk of sexually transmitted infections including HIV, intimate partner violence, and maternal morbidity and mortality. ${ }^{23}$

The full immunization coverage was $49.6 \%$ in our study, which is lower than the national and the state coverage in Bihar. ${ }^{13}$ This is primarily because of the backward districts, Munger (Bihar) and Darrang (Assam), in the present study. Both districts have poor maternal and child health indicators, with full immunization coverage as low as $40 \%$ in Darrang. ${ }^{13}$ Hindu families have a significantly higher probability of 
full immunization coverage of children aged 12-23 compared to non-Hindus (primarily Muslims). Similarly, full immunization was higher in rural areas compared to urban slums. Previous studies had similar findings of less concentrated child immunization among Muslims than non-Muslims. ${ }^{10,11}$ Evidence suggest that child immunization is lower in urban slums, probably due to social exclusion, lack of awareness, and limited access to services. ${ }^{24}$

Our findings suggest a higher probability of full-immunization of 12-23 years old children in the lower-income group than the higherincome group (inequality favours poorer children). This does not concur with many studies reporting a direct association of wealth with immunization status. This can be understood from three possible scenarios. ${ }^{10,11}$ Firstly, these studies are based on the national health surveys and big sample size, while our study is based on two poor performing areas in the Empowered Action Group states with low full immunization coverage. Secondly, states like Bihar and Assam have a large proportion of the population in the lower wealth quintiles (nearly two-thirds) compared to other states in India. ${ }^{25}$ Lastly, the difference between the incomes of the two groups (lower and higher-income) is small compared to the wealth quintiles in other studies. However, our results corroborate with a study assessing wealth-based inequality in immunization using NFHS-4 data. The study reported that inequality favoured the poor in Bihar and Odisha with low full-immunization coverage. ${ }^{10}$ The most likely explanation for this paradox could be strengthened move by the government under Mission Indradhanush to complete the immunization of all under-5 with special focus on the most marginalized and poor communities. ${ }^{5}$

Maternal education widened the gap of inequality in immunization coverage between the higher and lower-income groups. This is consistent with other studies from Bihar and Assam, and other states of India. ${ }^{10,11}$ On the contrary, the caste and age of the child narrowed down the gap of inequality in immunization coverage. Our findings reflect a minimal difference in the marginalized or non-marginalized communities for the immunization coverage as they narrow down the gap in inequality. Narrowing of the inequality by age suggests that there is a delay in the receipt of vaccines among under-5; as a result, the vaccines supposed to be received before 23 months are received until five years. We concur with the earlier studies citing delay in the coverage among under- $5 .{ }^{26}$ Additionally; studies reported that children born in Muslim families, to mothers with lower maternal education, at home, and with low birth weight have higher chances of delayed immunization. ${ }^{26}$

\subsection{Limitations of the study}

The study results should be interpreted considering the following limitations. The small sample size of the study and selected geographies in which the study was conducted restrict the generalizability of the findings. We recorded immunization status based on the entry in the card by the health worker, which is argued to be incomplete sometimes.

\section{Conclusions}

We conclude that full immunization coverage is common among Hindus than non-Hindus and inhabitants of rural areas than urban slums. The income-based inequality in the full immunization coverage of 12-23 years old children favoured the poor, which was increased by maternal education and the place of residence and decreased by caste and age of the child. Considering the ambition of $>90 \%$ full immunization coverage of under-5 children, we ought to concretize plans and strategies to prevent drop-outs. Engagement with the local stakeholders and political leaders for awareness generation and community mobilization, prioritization of certain castes, religious communities, and hardto-reach populations, and capacity building of the health staff for effective communication with populations should be undertaken. There is a need to undermine and strengthen the determinants of child health and immunization, such as maternal education and women empowerment for sustainable achievements.

\section{Role of funding source}

The study was a part of the project supported by ITC, India, under corporate social responsibility (CSR). The donor was not involved in any component of the study.

\section{Author contribution}

SS wrote the full manuscript, SM conducted the study and reviewed the final manuscript, AJ performed the analysis, and SM edited the final version of the manuscript.

\section{Declaration of competing interest}

The authors declare that there is no conflict of interest.

\section{Acknowledgement}

The authors would like to thank the participants of this study for contributing their time. In addition, the authors are grateful for the assistance of field investigators for their help with data collections, and district team lead for his support to field investigators. We extend our thanks to Ajay Singh and Rachna Patel for developing the questionnaire and monitoring the data collection.

\section{References}

1 Global Alliance for Vaccines and Immunization (GAVI). Immunization and the Sustainable Development Goals. Geneva, Switzerland: GAVI, The Vaccine Alliance; 2019. Accessed date https://www.gavi.org/our-alliance/global-health-developme nt/sustainable-development-goals. Accessed July 15, 2020.

2 Global Alliance for Vaccines and Immunization (GAVI). Cost-Effective. Geneva, Switzerland: GAVI, The Vaccine Alliance; 2020. Accessed date https://www.gavi. $\mathrm{org} /$ vaccineswork/value-vaccination/cost-effective. Accessed March 13, 2020.

3 World Health Organization. Immunization Coverage. Geneva, Switzerland: World Health Organization; 2020. Accessed date https://www.who.int/news-room/fact-sh eets/detail/immunization-coverage. Accessed June 15, 2020.

4 Ministry of Health and Family Welfare, Government of India. Immunization. New Delhi, India: Government of India; 2020. Accessed https://nhm.gov.in/index1.php? lang $=1 \&$ level $=2 \&$ sublinkid $=824 \& l i d=220$. Accessed August 12, 2020.

5 Gurnani V, Haldar P, Aggarwal MK, et al. Improving vaccination coverage in India: lessons from Intensified Mission Indradhanush, a cross-sectoral systems strengthening strategy. BMJ. 2018;363, k4782.

6 Donfouet HPP, Agesa G, Mutua MK. Trends of inequalities in childhood immunization coverage among children aged 12-23 months in Kenya, Ghana, and Côte d'Ivoire. BMC Publ Health. 2019;19:988.

7 Arokiasamy P, Pradhan J. Measuring wealth-based health inequality among Indian children: the importance of equity vs efficiency. Health Pol Plann. 2011;26(5): 429-440.

8 Lauridsen J, Pradhan J. Socio-economic Inequality of Immunization Coverage in Indiavol. 1. Health Econ Rev; 2011.

9 Pande RP, Yazbeck AS. What's in a country average? Wealth, gender, and regional inequalities in immunization in India. Soc Sci Med. 2003:57(11):2075-2088.

10 Debnath A, Bhattacharjee $\mathrm{N}$. Wealth-based inequality in child immunization in India: a decomposition approach. J Biosoc Sci. 2018 May;50(3):312-325.

11 Srivastava S, Fledderjohann J, Upadhyay AK. Explaining socioeconomic inequalities in immunisation coverage in India: new insights from the fourth National Family Health Survey (2015-16). BMC Pediatr. 2020 Dec;20(1):1-2.

12 Singh S, Srivastava S, Upadhyay AK. Socio-economic inequality in malnutrition among children in India: an analysis of 640 districts from National Family Health Survey (2015-16). Int J Equity Health. 2019;18(1):203.

13 International Institute for Population Sciences (IIPS) and ICF. National Family Health Survey (NFHS-4), 2015-16: India. Mumbai: IIPS; 2017.

14 Ministry of Home Affairs. Annual Health Survey Bulletin 2011-2012. New Delhi, India: Government of India; 2012.

15 Erreygers G. Correcting the concentration index. J Health Econ. 2009;28:504-515.

16 O'Donnell O, Doorslaer EV, Wagstaff A, Lindelow M. Analyzing Health Equity Using Household Survey Data a Guide to Techniques and Their Implementation. World Bank. The concentration Index; 2008:95.

17 Fairlie RW. An extension of the Blinder-Oaxaca decomposition technique to logit and probit models. J Econ Soc Meas. 2005;30(4):305-316.

18 Government of India Census, 2013. New Delhi, India: Government of India; 2011. Accessed date http://www.censusindia.gov. Accessed March 10, 2020. 
19 Kiross GT, Chojenta C, Barker D, Tiruye TY, Loxton D. The effect of maternal education on infant mortality in Ethiopia: a systematic review and meta-analysis. PloS One. 2019;14(7). https://doi.org/10.1371/journal.pone.0220076. e0220076.

20 Hasan MT, Soares Magalhaes RJ, Williams GM, Mamun AA. The role of maternal education in the 15-year trajectory of malnutrition in children under 5 years of age in Bangladesh. Matern Child Nutr. 2016;12(4):929-939.

21 Saloi M, Baruah KK, Ojah J. A study of factors associated with teenage pregnancies in comparison with pregnant women of 20-29yrs in Boko, Assam. Int J Health Sci Res 2017;7(4):18-22.

22 Santhya KG, Acharya R, Pandey N, et al. Understanding the Lives of Adolescents and Young Adults (UDAYA) in Bihar, India. New Delhi, India: Population Council; 2016. Accessed https://www.popcouncil.org/uploads/pdfs/2017PGY_UDAYA-BiharR eport.pdf. Accessed October 7, 2020.
23 Paul P. Maternal age at marriage and adverse pregnancy outcomes: findings from the India human development survey, 2011-2012. J Pediatr Adolesc Gynecol. 2018;31(6): 620-624.

24 Singh S, Sahu D, Agrawal A, Vashi MD. Ensuring childhood vaccination among slums dwellers under the National Immunization Program in India-challenges and opportunities. Prev Med. 2018;112:54-60.

25 Barman S, De P. Socio-economic inequality of child immunization in the eastern and north-eastern states of India. Demography India Special Issue. 2017:16-26.

26 Choudhary TS, Reddy NS, Apte A, et al. Delayed vaccination and its predictors among children under 2 years in India: insights from the national family health survey-4. Vaccine. 2019;37(17):2331-2339. 